\title{
Effect of deposition parameters on TiAlN coating using pulsed DC CFUBMS
}

\author{
P. Mandal ${ }^{* 1}$, B. D. Beake ${ }^{2}$ and S. Paul ${ }^{3}$
}

This paper aims to investigate the parametric effect of deposition and target frequency on the mechanical properties and machining performance of the TiAIN coatings deposited in a dual cathode pulsed dc CFUBMS system. Coating composition is not directly dependent on deposition temperature or target frequency individually but increase in both the parameters has led to Al rich coating. The coating thickness is influenced by target frequency only. The fatigue fracture resistance of the TiAIN coating has been evaluated by the nanoimpact test and it has been found to be at least as good as commercial $\mathrm{Ti}_{0.5} \mathrm{Al}_{0.5} \mathrm{~N}$ coating deposited on cemented carbide. In dry machining SAE 1037 steel, it has been observed that the resistance to crater wear is influenced by target frequency. Simultaneous increase in the deposition temperature and target frequency has provided improved resistance to crater wear due to their favourable influence on the coating thickness and Al percentage.

Keywords: TiAIN, CFUBMS, Pulsed DC, Coating, Machining

\section{Introduction}

PVD coated tools are preferred to CVD coated tools due to lower deposition temperature, better compositional control of coating and minimisation of the thermal residual stress. The deposition of PVD TiN coatings on cutting tools has been widely used since the mid 1970s as it provides benefit in terms of machining performance as well as tool life in comparison with uncoated tools. ${ }^{1}$ However, in actual machining, as the cutting speed increases the temperature at tool workpiece interface is so high $\left(>700^{\circ} \mathrm{C}\right)$ that $\mathrm{TiN}$ layer gets oxidised (at $550^{\circ} \mathrm{C}$ ) and forms a poor adherent and brittle $\mathrm{TiO}_{2}$ layer on the top of TiN layer. Therefore, compressive stresses are developed in the oxide layers and spallation takes place. As a result, protecting ability of the TiN coating is lost as has been reported by Munz. ${ }^{2}$ Since the mid 1980s, TiAlN coatings had been successfully developed as a promising alternative to TiN coated cutting and forming tools. Munz ${ }^{2}$ developed TiAlN coating using sputter ion plating process and reported the performance of TiAlN coated drills to be two times better than that of TiN coated ones. He also reported the advantages of TiAlN coated tools such as improved resistance to oxidation (oxidation occurs at $800^{\circ} \mathrm{C}$ ), high hardness, high corrosion resistance and lower thermal conductivity.

TiAlN coatings have been successfully deposited by different PVD processes like ion plating, cathodic arc deposition as well as closed field unbalanced magnetron sputtering (CFUBMS) and recently pulsed DC CFUBMS. The use of pulsed DC CFUBMS successfully

Department of Mechanical Engineering, Indian Institute of Technology, Kharagpur, Kharagpur, West Bengal 721 302, India

*Corresponding author, email 200712mum@gmail.com addresses the issues of low deposition rate and target poisoning observed by Kelly et $a l^{3}$ The effect of different deposition parameters on mechanical and tribological properties of TiAlN coating deposited by DC-CFUBMS had been thoroughly investigated. Kim et al. ${ }^{4}$ have studied the effect of $\mathrm{N}_{2}$ partial pressure on deposition rate and hardness of TiAlN coating and found that low $\mathrm{N}_{2}$ partial pressure resulted in high deposition rate but low hardness.

Some studies have also been reported on characterisation of TiAlN film deposited via pulsed DC CFUBMS. Shum et al. ${ }^{5}$ discussed the effect of Al target current on deposition rate, film thickness, film structure, hardness, adhesive strength, and friction coefficient. They reported that the deposition rate, film thickness, hardness and friction coefficient $(0 \cdot 55-0 \cdot 65)$ increased with increase in $\mathrm{Al}$ target current $(0-7 \mathrm{~A})$ while scratch adhesion (around $90 \mathrm{~N}$ ) remained more or less same and columnar film structure was obtained. Astrand et al. ${ }^{6}$ discussed the effect of $\mathrm{N}_{2}$ partial pressure on growth rate of film and they observed that highest growth rate $\left(23 \mathrm{~nm} \mathrm{~min}{ }^{-1}\right.$ ) was obtained for lowest $\mathrm{N}_{2}$ partial pressure $(0.375 \mathrm{mtorr} / 0 \cdot 05 \mathrm{~Pa})$. Zywitzki et al. ${ }^{7}$ showed the effect of substrate bias voltage on hardness, residual stress, film structure, and elastic modulus. They observed that with increase in negative substrate bias voltage $(0-80 \mathrm{~V})$, microstructure became denser, and hardness, residual stress and elastic modulus increased proportionally. Barshilia et $a l^{8}{ }^{8}$ also studied the effect of substrate bias voltage on hardness and ion current. The hardness and ion current both increased with increase in bias voltage $(-30$ to $-75 \mathrm{~V})$ and after that no significant improvement was noted.

Although the influence of some of the deposition parameters ( $\mathrm{Al}$ target current, partial pressure of $\mathrm{N}_{2}$ and

(C) 2012 Institute of Materials, Minerals and Mining Published by Maney on behalf of the Institute

Received 2 February 2012; accepted 16 November 2012 DOI 10.1179/1743294412Y.0000000091 
substrate bias voltage) on coating properties has been well established a full parametric study has yet to be undertaken. The effect of deposition temperature, target frequency, bias frequency on the properties of TiAlN coatings deposited via pulsed DC CFUBMS has not been reported and importantly, their influence on machining performance has also not been addressed. Moreover, deposition of TiAlN is undertaken by several researchers with alloyed targets. ${ }^{4,9-12}$ Alloyed targets are costly and once an alloyed target is chosen, the chemistry of the coating ( $\mathrm{Ti} / \mathrm{Al}$ ratio) cannot be altered. Therefore, in the present study, pure Ti and Al targets have been used that directly affects economics of coating. The objective of this paper is to investigate the parametric effect of deposition temperature and target frequency on mechanical properties as well as machining performance of the TiAlN coating deposited using pure targets in dry turning of SAE 1037 steel.

\section{Experimental}

\section{Deposition}

TiAlN coatings were deposited in a dual cathode pulsed DC closed field unbalanced magnetron system (VTC 01A, manufactured by Milman Thin Film systems Pvt. Ltd, India). Ti and Al targets with purity better than $99 \cdot 99 \%$ and dimensions of $254 \times 127 \mathrm{~mm}$ and thickness of $12 \mathrm{~mm}$ were used during the deposition. Coatings were deposited on three different types of substrates namely HSS block of M2 grade $(10 \times 10 \times 20 \mathrm{~mm})$, low carbon steel (SAE 1010) disc shaped coupons $(\phi$ $25 \times 10 \mathrm{~mm}$ ) and uncoated tungsten carbide inserts of grade K10 $(94 \% \mathrm{WC}+6 \% \mathrm{Co})$ and nominal geometry of SNMA 120408. Before deposition, all substrates except the inserts were polished to a roughness of $R_{\mathrm{a}}=0.05 \mu \mathrm{m}$ and ultrasonically cleaned using acetone, isopropyl alcohol and trichloroethylene. Before transferring the samples to the deposition chambers, they were dried using hot air. The substrate stage had a two-fold rotation facility and rotated at $4 \mathrm{rev} \mathrm{min}^{-1}$ during deposition. Bipolar pulsed DC power supplies (advanced energy pinnacle plus) were used. Cathodes were energised in current mode and the substrate was energised in voltage mode. A base pressure of better than $2 \times 10^{-3} \mathrm{~Pa}$ was achieved before initiating deposition, which was very similar to the base pressure reported by Musil and Hruby $^{9}$ and Zhou et al. ${ }^{13}$ The deposition cycle consisted of sputter cleaning of the targets with shutters in closed position, followed by ion etching. Ion etching was conducted for 15 min at a bias voltage of $-500 \mathrm{~V}$ with a pulsed frequency of $250 \mathrm{kHz}$ at Ar pressure of $0.16 \mathrm{~Pa}$ with titanium target current set to $1 \mathrm{~A}$. Then, a titanium interlayer of around $200 \mathrm{~nm}$ thickness was deposited which was followed by TiN interlayer. The relevant deposition conditions for all the coatings are summarised in Table 1.

\section{Characterisation tests}

The surface morphology and fractography of the coated HSS samples were observed under a scanning electron microscope (Carl Zeiss EVO 60) fitted with an EDX analyser (INCA FET 3X). The surface roughness of the coated samples was measured on coated HSS samples at ten different locations using contact type surface profilometer (Taylor - Hobson Surtronic 3+) with a cutoff length of $0.8 \mathrm{~mm}$. The composite Vickers microhardness of the coating was also measured on coated HSS samples using a load of $1 \mathrm{~N}$ with a dwell time of $15 \mathrm{~s}$ in a LECO LM-700 microhardness measurement system. For each coated HSS sample, ten measurements were undertaken and their average has been reported.

Sample no. S6, deposited on HSS, was selected for further nanomechanical characterisation. A NanoTest system (Micro Materials Ltd, Wrexham, UK) was used for nanoindentation and nanoimpact testing. In the nanoindentation tests, a Berkovich indenter was used. Two types of test were performed: first, 40 repeat conventional load-unload tests to a peak load of $25 \mathrm{mN}$ and second, load-partial unload multicycle indentation to $100 \mathrm{mN}$ maximum load for depth profiling of hardness and modulus. For the nanoimpact testing, a solenoid connected to a timed relay was used to produce the repetitive probe impacts on the surface. A cube corner diamond indenter test probe was accelerated from a distance of $15 \mu \mathrm{m}$ from the surface to produce each impact at applied loads of 25, 50 and $100 \mathrm{mN}$ for rapid fracture. Five repeat tests were performed for $25 \mathrm{mN}$ load and three repeat tests were performed for 50 and $100 \mathrm{mN}$ loads at different locations on the sample.

The adhesion of the coatings to the substrate was measured by TR-101 M5 DUCOM Scratch Tester with a Rockwell $\mathrm{C}$ diamond indenter of tip radius $0.2 \mathrm{~mm}$. All the above tests were performed on coated HSS M2 samples. The indenter was drawn across the coating at a speed of $6 \mathrm{~mm} \mathrm{~min}{ }^{-1}$ over a scratch length of $15 \mathrm{~mm}$. The normal load during scratching was varied from 10 to $120 \mathrm{~N}$. During scratching, the tangential force was continuously monitored. The scratch adhesion

Table 1 Deposition conditions for TiAIN coatings

Deposition conditions

Variable parameters

\begin{tabular}{|c|c|c|c|c|c|c|}
\hline $\begin{array}{l}\text { Sample } \\
\text { no. }\end{array}$ & $\begin{array}{l}\text { Deposition } \\
\text { temperature } /{ }^{\circ} \mathrm{C}\end{array}$ & $\begin{array}{l}\text { Target } \\
\text { frequency/kHz }\end{array}$ & $\begin{array}{l}\mathrm{N}_{2} \text { flowrate/ } \\
\text { sccm }\end{array}$ & $P_{\mathrm{Ar}} / \mathrm{Pa}$ & $P_{\mathrm{N} 2} / \mathrm{Pa}$ & $\begin{array}{l}\text { Fixed } \\
\text { parameters }\end{array}$ \\
\hline S2 & 270 & 100 & 12 & $0 \cdot 16$ & 0.04 & Ar flowrate: 15 sccm; \\
\hline S3 & 300 & 100 & 12 & $0 \cdot 16$ & 0.04 & Ti target current: $3 \mathrm{~A}$; \\
\hline S4 & 350 & 100 & 12 & $0 \cdot 16$ & 0.04 & Al target current: $4 \mathrm{~A}$; \\
\hline S5 & 250 & 250 & 10 & $0 \cdot 20$ & 0.07 & substrate bias voltage: \\
\hline S6 & 300 & 250 & 10 & $0 \cdot 20$ & 0.07 & -50 V; duty cycle: $80 \%$ \\
\hline S7 & 350 & 250 & 10 & 0.20 & 0.07 & \\
\hline S8 & 300 & 200 & 10 & $0 \cdot 20$ & 0.07 & \\
\hline S9 & 300 & 300 & 10 & 0.20 & 0.07 & \\
\hline
\end{tabular}


is quantified by the normal load at which the coating fails (critical load or LC). In the present work, the critical load has been determined by the sudden increase in the ratio of the tangential or traction force to the normal force during scratching. This typically coincides with $\mathrm{L}_{\mathrm{C} 3}$ type of failure, which indicates initiation of removal of the coating as described by He et al. ${ }^{14}$

To study the tribological performance of the coatings ball-on-disc tests were performed with a tribometer (TR201 M3 DUCOM). The tests were undertaken on disc shaped low carbon steel coupons at a normal load $10 \mathrm{~N}$ using $5 \mathrm{~mm}$ diameter cemented carbide balls $(94 \% \mathrm{WC}$ and $6 \% \mathrm{Co}$ ) with a sliding speed of $200 \mathrm{~mm} \mathrm{~s}^{-1}$ under ambient conditions $\left(25^{\circ} \mathrm{C}\right.$ and $50 \%$ relative humidity). The normal and tangential forces were continuously monitored during the test enabling the coefficient of friction to be determined from Amontons law. The depth of the wear track was measured at five different locations using a contact type surface profilometer (Taylor Hobson Surtronic 3+).

\section{Machining test: turning of medium carbon steel}

The machining performance of the TiAlN coated tungsten carbide inserts was evaluated by dry turning of medium carbon steel (SAE 1037) bars at a cutting speed of $160 \mathrm{~m} \mathrm{~min}^{-1}$, feed of $0.2 \mathrm{~mm} \mathrm{rev}^{-1}$ and a depth of cut of $2 \mathrm{~mm}$. The cutting tool had an inclination angle of $-6^{\circ}$, an orthogonal rake angle of $-6^{\circ}$ and a nose radius of $0.8 \mathrm{~mm}$. Machining was interrupted at regular intervals and the rake and flank faces of the cutting tool were inspected under a stereo zoom microscope (Olympus model SZ 1145TR PT zoom stereo microscope) fitted with a digital photo micrograph system (Olympus C-5060 wide zoom). The cutting tools were ultrasonically cleaned in acidic solution before such inspection to remove any work material built-up on the rake face. The average and the maximum flank wears were determined from the photo micrographs. Cutting forces were monitored during machining by employing piezoelectric dynamometer (Kistler Instruments AG, Switzerland; type: 9257B) with matching charge amplifier (model: 5015A1000) to determine the apparent coefficient of friction at the chip tool interface during machining.

\section{Results and discussion}

\section{Coating composition, microstructure, thickness and surface roughness}

The chemical composition of as deposited TiAlN coatings obtained by bulk EDX analysis is shown in Table 2. The atomic percentage of $\mathrm{Ti} / \mathrm{Al}$ is close to $1: 1$ for these

Table 2 Chemical composition of deposited TiAIN

\section{Atomic percentage of elements}

\begin{tabular}{llllll}
\cline { 2 - 4 } Sample no. & $\mathrm{Ti}$ & $\mathrm{Al}$ & $\mathrm{N}$ & $\mathrm{Fe}$ & $\frac{\mathrm{Al}}{\mathrm{Ti}+\mathrm{Al}}$ \\
\hline S2 & 30.40 & 33.84 & 33.45 & 2.31 & 52.68 \\
S3 & 27.25 & 26.31 & 43.35 & 3.09 & 49.12 \\
S4 & 28.42 & 27.46 & 42.36 & 1.66 & 49.23 \\
S5 & 26.83 & 29.37 & 42.99 & 0.81 & 52.26 \\
S6 & 29.65 & 29.52 & 40.83 & 0.00 & 49.90 \\
S7 & 22.08 & 28.50 & 48.63 & 0.79 & 56.35 \\
S8 & 22.14 & 29.02 & 48.20 & 0.63 & 56.72 \\
S9 & 21.39 & 27.92 & 50.12 & 0.57 & 56.62 \\
\hline
\end{tabular}

coatings. For some coatings, the Al percentage was slightly greater (to $57 \%$ ), so they could be considered as Al rich AlTiN ${ }_{x}$ coatings. Sample S2-S4 are some of the thinnest samples having highest $\mathrm{Fe}$ percentage. $\mathrm{Fe}$ is detected in the analysis due to low coating thickness of the samples. It seems that variations in individual parameters, such as deposition temperature and target frequency, have almost no effect on chemical composition of the deposited coating. Increasing target frequency and temperature simultaneously (for samples S7, S8 and S9) produced $\mathrm{Al}$ rich $\mathrm{AlTiN}_{\mathrm{x}}$ coatings.

The surface morphology and the fractograph of two selected coatings (S7 and S9) are shown in Fig. 1. All the coatings show compact coating structure with submicrometre agglomerated grain size as observed under SEM (Fig. $1 a$ and $c$ for $\mathrm{S} 7$ and $\mathrm{S} 9$ respectively). Some samples such as S8 and S9 (Fig. 1d for S9) show very compact bottom layer structure followed by dense columnar top layer. The thickness of all the coatings was in the range of $1 \cdot 2-2 \cdot 2 \mu \mathrm{m}$ (e.g. S9 is $\sim 2.06 \mu \mathrm{m}$ thick as shown in Fig. 1d) as listed in Table 3. The samples S5-S9 deposited at higher target frequency $(200-300 \mathrm{kHz})$, have higher thickness (around 1.7-2.2 $\mu \mathrm{m}$ ) compared to the samples (S2-S4), deposited at a lower target frequency of $100 \mathrm{kHz}$. This may be attributed to reduction in target poisoning with increase in target frequency thus providing higher deposition rate as reported by Kelly et al. ${ }^{3}$ It cannot be concluded from Table 3 that increase in target frequency directly results in higher thickness. The flowrate and partial pressure of $\mathrm{N}_{2}$ may also play an important role in the deposition, as has been reported for pulsed DC CFUBMS system by Astrand et al. ${ }^{6}$ Moreover, it seems that variation in deposition temperature has almost no effect on coating thickness. Variation in surface roughness of all TiAlN coated samples is listed in Table 3. All the samples have roughness around 0.08$0.13 \mu \mathrm{m}$ except S3 having a roughness of $\sim 0.2 \mu \mathrm{m}$. Within the range studied, varying the deposition temperature or target frequency has no clear effect on surface roughness. Kim et al. ${ }^{4}$ similarly observed no significant variation in surface roughness of the coating when $\mathrm{N}_{2}$ partial pressure was varied between $0 \cdot 3-0.5$ mTorr (0.039-0.067 Pa).

\section{Micro- and nanomechanical properties}

The composite microhardness of all deposited coatings is found to be in the range of $20-25 \mathrm{GPa}$ under $1 \mathrm{~N}$ test load, as listed in Table 3. No systematic parametric effect of deposition temperature and target frequency could be discerned. Table 3 indicates that the first five samples (S2-S6) have slightly higher composite microhardness than last three (S7-S9). This may be due to the presence of high Al percentage in the film. The first five samples (S2-S6) have Al percentage less than 53\% whereas last three samples (S7-S9) have Al percentage more than $56 \%$. Higher Al percentage means presence of more amount of soft hcp AlN phase as reported by PalDey and Deevi ${ }^{15}$ as well as Santana et al. ${ }^{16}$ in the film, which may have provided reduced hardness.

Sample 6 was selected for further nanomechanical characterisation by nanoindentation and nanoimpact testing because it showed the highest critical load $(86.4 \mathrm{~N})$ in scratch testing. Analysis of unloading curves provides hardness of $(21.9 \pm 6.0) \mathrm{GPa}$ and reduced elastic modulus of $(250 \pm 36) \mathrm{GPa}$. Assuming a Poisson ratio of $0 \cdot 2$ for the coating, this converts to a Young's 


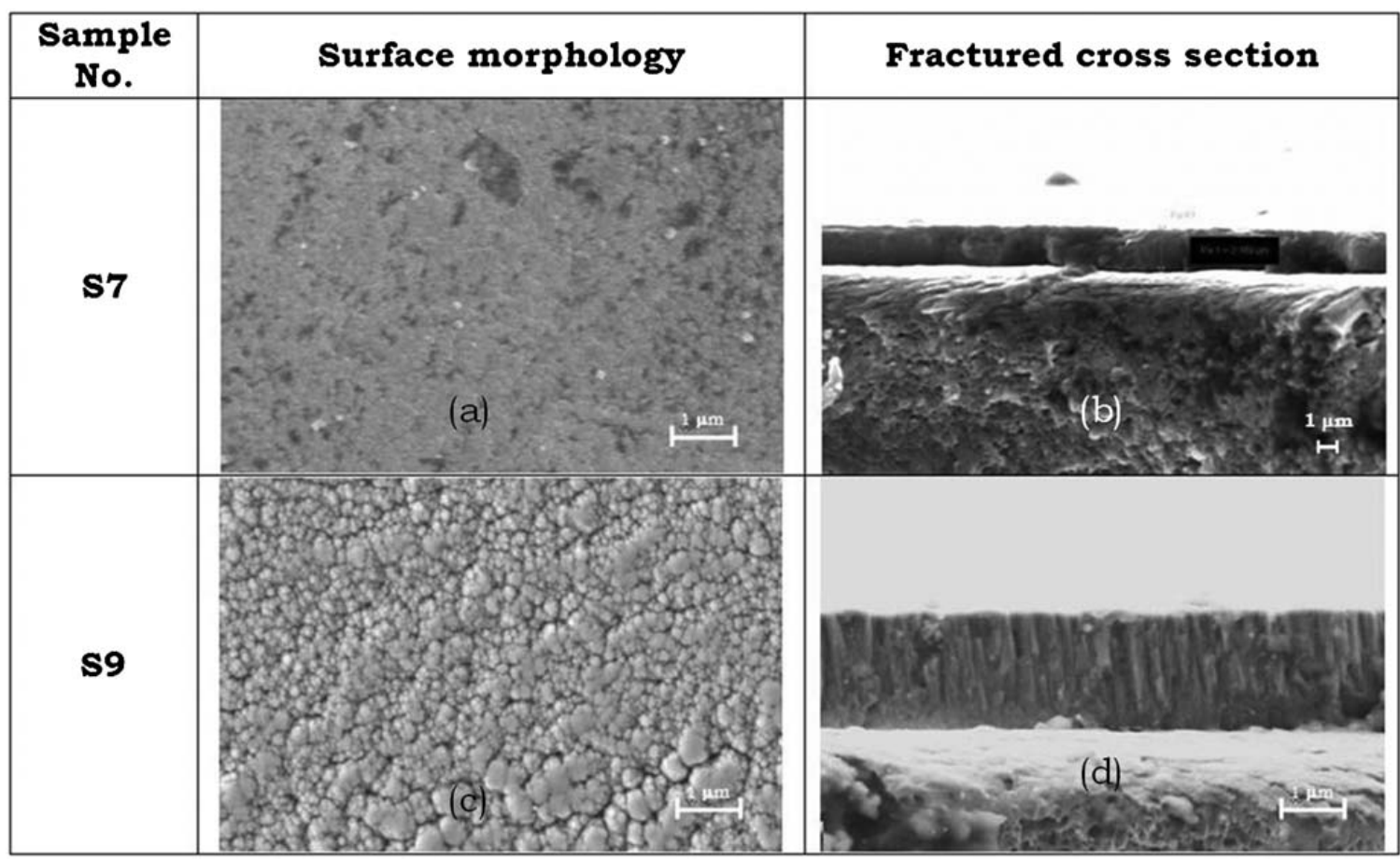

ONLINE

1 Surface morphology and fractograph of two selected samples $-\mathrm{S7}$ and S9

(elastic) modulus of $307 \mathrm{GPa}$. The indentation behaviour was compared with a TiN sample for benchmarking. Discrete steps due to fracture are clearly visible in TiN coating, which are absent for sample S6, suggesting improved toughness of sample S6 over TiN coating, as shown in Fig. 2. Depth profiling by nanoindentation was performed to confirm that the hardness varies little with depth at under $1 / 10$ coating thickness and to investigate whether the elastic modulus determined from the $25 \mathrm{mN}$ could be considered as a coating-only value. The recent ISO standard for depth sensing indentation (ISO 14577-4) notes that since the elastic stress field extends further than the plastic stress field a better strategy for coating-only modulus is to extrapolate to zero depth rather than rely on the $10 \%$ rule that is not correct for modulus. Extrapolation suggests a value of reduced indentation modulus around $268 \mathrm{GPa}$ (i.e. a little higher than the value from the $25 \mathrm{mN}$ tests, which have a contribution from the less stiff HSS substrate) and so a better value for the true elastic modulus of the coating is $\sim 336 \mathrm{GPa}$, using Poisson ratio of $0 \cdot 2$. Figure 3 shows the hardness was $\sim 23 \mathrm{GPa}$ (i.e. consistent with the $25 \mathrm{mN}$ tests) up to $\sim 300 \mathrm{~nm}$, decreasing with depth beyond that due to the plastic field extending into the softer substrate. The large error bars are due to the high surface roughness, which is a significant fraction of the indentation depth.
The plasticity index (PI, plastic work done in indentation/total work done) has been used to predict the tribological behaviour of coated tools under cutting condition. Beake et al. ${ }^{10}$ noted that high PI is a critical factor for interrupted cutting applications like milling but in case of continuous cutting applications like turning, the requirement for high PI is less critical and high hardness is a more dominant factor governing tool life. They also reported that in turning, tool life of cemented carbide (WC-Co) insert is longer when PI is relatively low (e.g. for TiAlN, or annealed AlTiN) than for higher PI coatings (e.g. $0 \cdot 50$ for $\mathrm{TiAlCrN}$ ). For sample S6, the PI was $\sim 0 \cdot 47$, which is very close to the other TiAlN coatings reported in the literature.

The fatigue fracture resistance of the sample S6 has been assessed by the nanoimpact test. The background to this test is provided in Refs. 17 and 18. It has proved highly effective in determining the fracture resistance of hard coatings under repetitive impact. ${ }^{18}$ Each test corresponds to 75 impacts. Figure 4 shows illustrative test results at 25, 50 and $100 \mathrm{mN}$. When the accelerating load was $25 \mathrm{mN}$ no fracture was obtained in any of the five repeat tests. When the accelerating load was increased coating fracture could be observed in some of the tests. Figure 4 shows coating fracture at $100 \mathrm{mN}$ after $\sim 45$ impacts. The behaviour of the coating under repetitive nanoimpact can be compared to results

Table 3 Coating thickness, surface roughness and composite microhardness of deposited TiAIN coatings

\begin{tabular}{llll}
\hline Sample no. & Coating thickness/ $\mu \mathrm{m}$ & Surface roughness $\boldsymbol{R}_{\mathrm{a}} / \mu \mathrm{m}$ & Composite microhardness/GPa \\
\hline S2 & 1.78 & 0.096 & 23.6 \\
S3 & 1.23 & 0.194 & 24.9 \\
S4 & 1.47 & 0.084 & 24.6 \\
S5 & 2.03 & 0.076 & $23 \cdot 1$ \\
S6 & 1.76 & 0.125 & $22 \cdot 6$ \\
S7 & 2.18 & 0.094 & $22 \cdot 1$ \\
S8 & 1.87 & 0.069 & $21 \cdot 7$ \\
S9 & 2.06 & 0.085 & \\
\hline
\end{tabular}



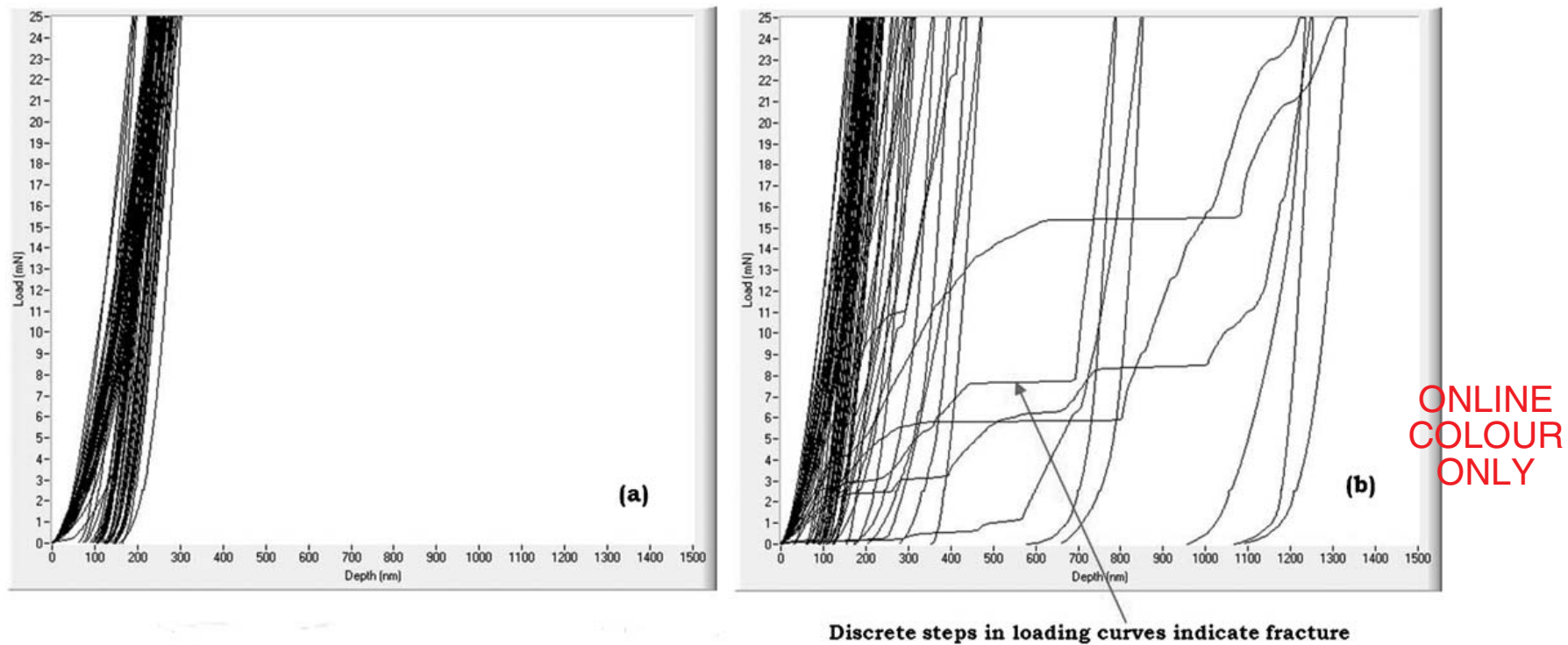

2 Loading unloading curve for a sample $\mathrm{S} 6$ and $b$ TiN sample (for bench marking) during nanoindentation

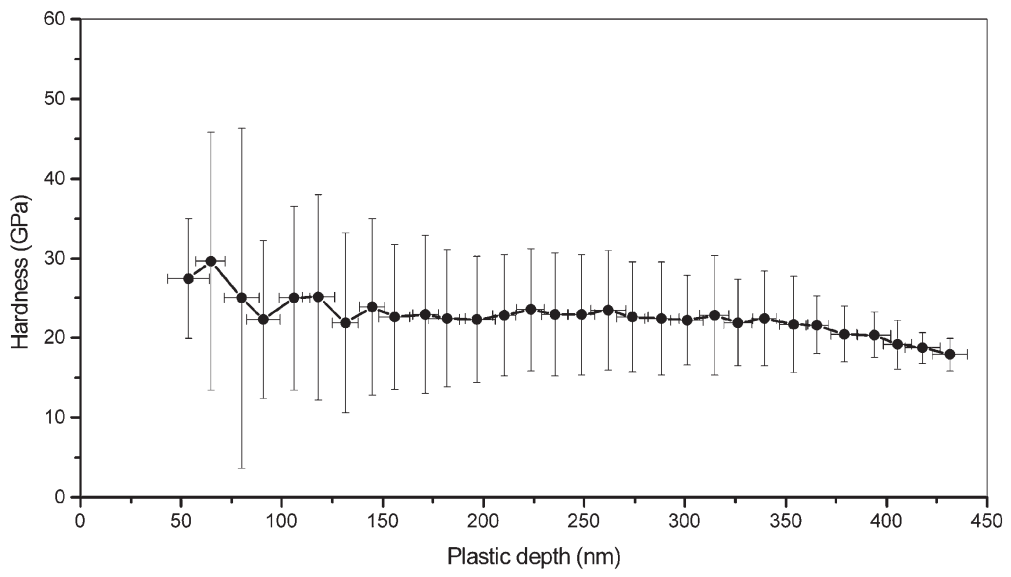

3 Nanohardness profile within coated sample S6 over depth of $>400 \mathrm{~nm}$

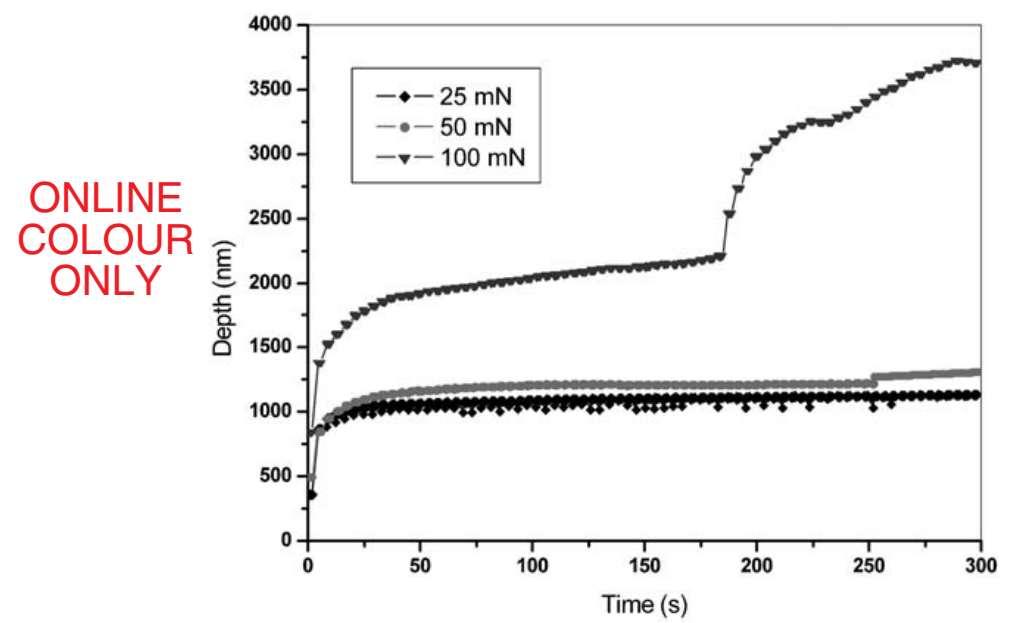

4 Variation in depth of indentation with number of impacts in nanoimpact test at 25,50 and $100 \mathrm{mN}$ accelerating force for 100 impacts reported previously (Fox-Rabinovich et al. ${ }^{19}$ ) for commercial $\mathrm{Ti}_{0.5} \mathrm{Al}_{0.5} \mathrm{~N}$ coated cemented carbide inserts. Using the same nanoimpact test with a slightly sharper indenter, they observed that the commercial TiAlN coated insert fractured almost immediately at only $15 \mathrm{mN}$ accelerating load (Fig. $3 a$ at page 5741 of FoxRabinovich et al. $\left.{ }^{19}\right)$. Although sample 6 showed higher fracture resistance than this commercial coating it has been deposited on HSS, a substrate with greater ductility than WC-Co, which may have influenced the strain accumulation under load and its propensity for cracking on repetitive impact.

\section{Scratch adhesion}

The failure of the coating has been identified by the sudden change in coefficient of friction. Table 4 lists the variation in critical load, in the range of $50-85 \mathrm{~N}$ for all the deposited coatings. It indicates an increase in scratch adhesion of the coating with increase in deposition temperature especially at low target frequency $(100 \mathrm{kHz})$. The same trend is not followed when depositions are done at higher target frequency $(200-300 \mathrm{kHz})$. The highest critical load has been found for sample S6, deposited at 
$300^{\circ} \mathrm{C}$ and $250 \mathrm{kHz}$ target frequency, possibly as the increase in target frequency leads to increase in ion current density and consequently enhanced adhesion.

\section{Coefficient of friction at chip tool interface and wear coefficient}

The coefficient of friction of a coated sample is commonly evaluated using the ball-on-disc test though the test conditions differ considerably from those in actual machining. There is no direct way to measure coefficient of friction during actual machining. Therefore, tangential cutting force and feed force have been measured during machining and coefficient of friction has been calculated using Merchant's circle diagram. ${ }^{20}$ Table 4 lists the coefficient of friction of all the coated inserts (S2-S9) along with an uncoated insert (S1) after 1 min machining of SAE 1037 steel with a cutting speed of $160 \mathrm{~m} \mathrm{~min}^{-1}$, feed of $0.2 \mathrm{~mm} \mathrm{rev}^{-1}$ and depth of cut of $2 \mathrm{~mm}$. All the coated inserts show lower friction coefficient than the uncoated insert. Deposition temperature and target frequency have little clear effect on coefficient of friction. The highest friction coefficient was found for sample S3, which is thinner and has the highest surface roughness. In the ball-on-disc experiment the performance of a wear resistant coating is evaluated by the wear coefficient, defined as volume of material removed to a product of normal load and sliding distance as explained by Bull et $a .^{21}$ Table 4 lists the dimensional wear coefficients, which were found to be in the range of $5.6-$ $9 \cdot 5 \times 10^{-6} \mathrm{~mm}^{3} \mathrm{~N}^{-1} \mathrm{~m}^{-1}$. These values compare favourably with previous reports on TiAlN coatings, $10 \times 10^{-6} \mathrm{~mm}^{3} \mathrm{~N}^{-1} \mathrm{~m}^{-1}$ as reported by Mo et al. ${ }^{22}$ and $20 \times 10^{-6}$ to $80 \times 10^{-6} \mathrm{~mm}^{3} \mathrm{~N}^{-1} \mathrm{~m}^{-1}$ by Li et al. ${ }^{23}$ With increased deposition temperature, the wear coefficient decreases, particularly for samples S5, S6 and S7, deposited at high target frequency $(250 \mathrm{kHz})$. However, the trend is not followed by samples S2, S3 and S4, deposited at low target frequency $(100 \mathrm{kHz})$. No clear effect of target frequency has been observed. The wear coefficient is lowest (for sample S7) when deposition was done simultaneously at high temperature $\left(350^{\circ} \mathrm{C}\right)$ and high target frequency $(250 \mathrm{kHz})$.

The most used wear model is Archer's wear equation and the dimensionless wear coefficient $K$ can be calculated using that equation

$$
\frac{V}{S}=K \frac{W}{H}
$$

where $V$ is the volume of worn away material, $s$ is the sliding distance, $W$ is the applied normal load, $H$ is the hardness of the coating material and $K$ is the dimensionless wear coefficient. From the above equation $K$ can be calculated as

$$
K=\frac{V}{s W} \times H
$$

where $V / s W$ actually indicates the dimensional wear coefficient. Therefore, $K$ is the product of dimensional wear coefficient $\left(\mathrm{mm}^{3} / \mathrm{N}-\mathrm{m}\right)$ and the hardness $(\mathrm{GPa})$ of the film. The dimensionless wear coefficient has been calculated and listed in Table 4. For all the samples, trends of both the dimensionless and dimensional wear coefficient are found to be very similar. No clear effect of target frequency was observed. Both the dimensionless and dimensional wear coefficient is found to be lowest (for sample S7) when deposition was done simultaneously at high temperature $\left(350^{\circ} \mathrm{C}\right)$ and high target frequency $(250 \mathrm{kHz})$.

The critical load characterises scratch adhesion whereas the wear coefficient in a ball-on-disk experiment provides resistance to wear. Both of them are dependent on parameters like coating thickness and substrate bias voltage. There is experimental evidence for an inverse correlation commonly existing between them for many coating systems. Takadoum and Bennani ${ }^{24}$ experimentally showed that with increasing thickness of ion plated TiN coatings on steel substrate, the adhesion decreased along with an increase in wear coefficient and for ion plated TiN coatings on stainless steel substrate, Bull et $a .^{25}$ reported that with an increase in the substrate bias voltage, the critical load decreases again with increase in wear rate. In the present work, all the coatings have been deposited at same substrate bias voltage and the coating thickness has been varied. The tight compositional range provides a useful sample set to investigate the correlation between scratch critical load and wear coefficient. By comparing samples S5-S9, deposited at higher target frequency $(200-300 \mathrm{kHz})$, the same trend for critical load with increasing coating thickness noted by Takadoum and Bennani ${ }^{24}$ was observed. Similarly for samples S2-S4, deposited at low target frequency $(100 \mathrm{kHz})$, the wear coefficient values follow the trend listed in Table 4. The present results indicate that if the deposition parameters are fixed, then the wear coefficient will vary inversely with critical load in agreement with these reports. The same is true for samples S2-S4 deposited at low target frequency $(100 \mathrm{kHz})$ as well as for samples S5, S6, S8 and S9 deposited at higher target frequency $(200-300 \mathrm{kHz})$. Sample S7 is the only exception where the wear coefficient

Table 4 Critical load, coefficient of friction and wear coefficient (dimensional and dimensionless) of deposited TiAIN

\begin{tabular}{|c|c|c|c|}
\hline Sample no. & $\begin{array}{l}\text { Critical } \\
\text { load } L_{\mathrm{C}} / \mathrm{N}\end{array}$ & $\begin{array}{l}\text { Coefficient of friction } \\
\text { as evaluated from machining }\end{array}$ & $\begin{array}{l}\text { Wear coefficient }\left(\times 10^{-6} \mathrm{~mm}^{3} \mathrm{~N}^{-1} \mathrm{~m}^{-1}\right) \\
\text { as measured in ball-on-disc experiment }\end{array}$ \\
\hline S2 & $55 \cdot 0$ & 0.54 & $8 \cdot 72$ \\
\hline S3 & $61 \cdot 5$ & 0.60 & $7 \cdot 23$ \\
\hline S4 & $77 \cdot 0$ & 0.53 & $7 \cdot 99$ \\
\hline S5 & $78 \cdot 2$ & 0.50 & $7 \cdot 83$ \\
\hline S6 & $86 \cdot 4$ & 0.50 & $7 \cdot 35$ \\
\hline S7 & $60 \cdot 0$ & 0.53 & $5 \cdot 63$ \\
\hline S8 & $77 \cdot 5$ & 0.53 & $8 \cdot 69$ \\
\hline S9 & $70 \cdot 0$ & 0.50 & $9 \cdot 52$ \\
\hline S1 (uncoated insert) & $\ldots$ & 0.68 & $\ldots$ \\
\hline
\end{tabular}
coatings 


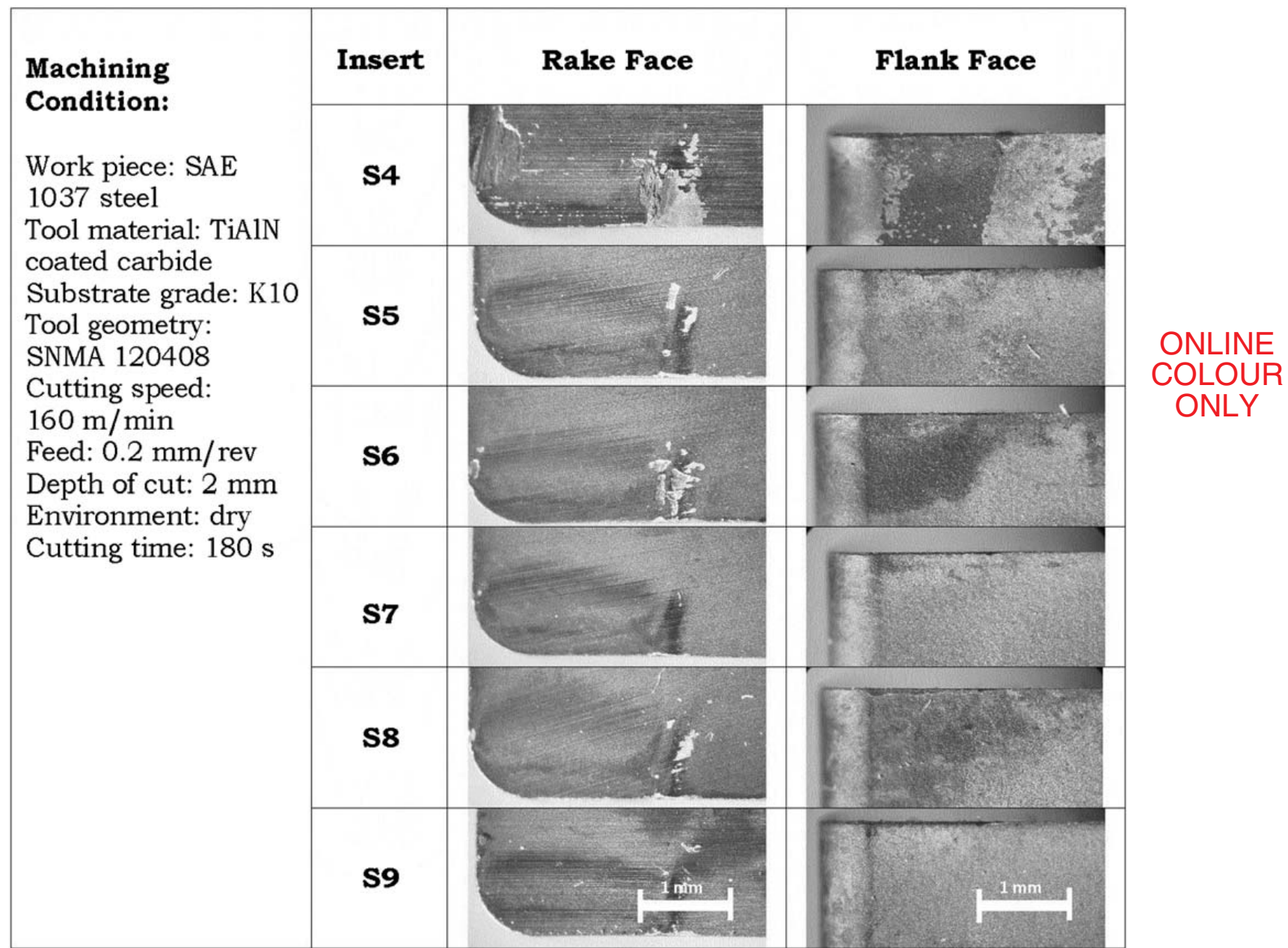

5 Nature of crater and flank wear of selected inserts after dry turning of SAE 1037 steel at cutting velocity of $160 \mathrm{~m} \mathrm{~min}^{-1}$, feed of $0.2 \mathrm{~mm} \mathrm{rev}^{-1}$ and depth of cut of $2 \mathrm{~mm}$

is found to be lowest though it shows comparatively lower critical load.

\section{Machining performance}

The machining performance of the coated inserts has been assessed using the tool wear criterion. For first $90 \mathrm{~s}$ of machining, flank wear for all the inserts has been found to be negligible. Even after 3 min of machining, none of the inserts show any significant flank wear as shown in Fig. 5. The maximum and average flank wear of all inserts was in the range of 48-118 and 20-60 $\mu \mathrm{m}$ respectively, as listed in Table 5. The maximum as well as average flank wear is highest for samples S3 and S4, which have lowest coating

Table 5 Maximum and average flank wear of TiAIN coated inserts during machining of SAE 1037 steel

\begin{tabular}{llll}
\hline $\begin{array}{l}\text { Cutting } \\
\text { time/s }\end{array}$ & $\begin{array}{l}\text { Sample } \\
\text { no. }\end{array}$ & $\begin{array}{l}\text { Max. flank } \\
\text { wear/ } \mu \mathrm{m}\end{array}$ & $\begin{array}{l}\text { Avg. flank } \\
\text { wear/ } \mu \mathrm{m}\end{array}$ \\
\hline $20-90$ & S2-S9 & Wear is negligible \\
180 & S2 & 60 & 37 \\
& S3 & 78 & 39 \\
& S4 & 117 & 59 \\
& S5 & 60 & 36 \\
& S6 & 60 & 28 \\
& S7 & 59 & 33 \\
& S8 & 48 & 23 \\
& S9 & 52 & 30 \\
\hline
\end{tabular}

thickness among all the samples. The result is found to be similar as discussed by Bouzakis et al. ${ }^{26}$ They experimentally showed that in milling, the average flank wear of cemented carbide inserts reduced with increase in coating thickness. Additionally, S3 and S4 have lowest Al \% among all the coatings. In dry turning, significant heat is generated at the tool workpiece interface due to high friction. As a result, oxidation occurs and a thin $\mathrm{Al}$ rich oxide layer is generated that protects the tool from further oxidation. ${ }^{2}$ For these two inserts as the amount of $\mathrm{Al}$ rich oxide is less, the machining performance is consistent yielding greater crater and flank wear than other inserts. It can be inferred that when depositions are undertaken at higher target frequency (200-300 kHz), the maximum and average flank wear becomes less compared to inserts deposited at low target frequency $(100 \mathrm{kHz})$. This would be attributed to enhanced wear resistance of the coating due to higher ionisation at higher target frequency. Variation in deposition temperature has no significant effect on flank wear.

Strikingly, it is noticeable that there is almost no correlation between wear coefficients of inserts with their machining performance in terms of flank wear. This may be attributed to the wide difference between wear test and machining test conditions. Machining test conditions result in high chip tool interface pressure and temperature, which are relatively less in ball-on-disc wear test. Further, in wear test, the linear speed of WCCo ball is $12 \mathrm{~m} \mathrm{~min}^{-1}$, whereas in machining, the 


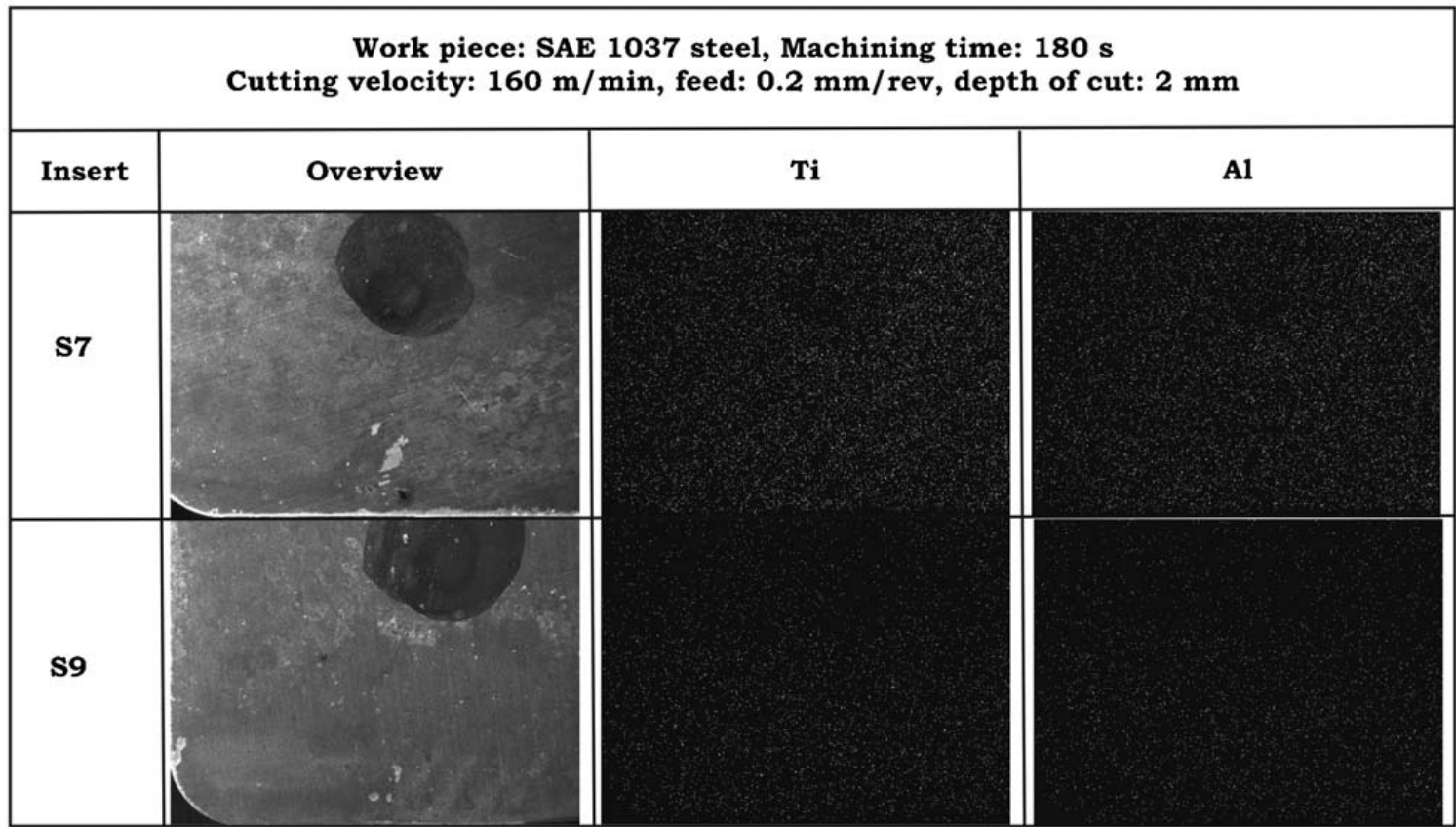

ONLINE

6 Elemental area mapping using EDX on inserts S7 and S9 after $180 \mathrm{~s}$ of dry turning of SAE 1037 steel at cutting speed of $160 \mathrm{~m} \mathrm{~min}^{-1}$, feed of $0.2 \mathrm{~mm} \mathrm{rev}{ }^{-1}$ and depth of cut of $2 \mathrm{~mm}$

cutting speed is $160 \mathrm{~m} \mathrm{~min}^{-1}$. The speed in machining is $>10$ times higher and that results in a very high cutting temperature (typically $500^{\circ} \mathrm{C}$ ) at the cutting zone. ${ }^{27}$ As an illustration of this, the contact pressure has been estimated for one of the samples (S9) in both tests. In the wear test, normal load $N=10 \mathrm{~N}$ and area of scar on the WC ball $A=0.305 \mathrm{~mm}^{2}$. Therefore, contact pressure $P_{\text {wear }}=N / A=32.77 \mathrm{~N} \mathrm{~mm}^{-2}(0.03 \mathrm{GPa})$. In machining test, normal load $N=1021.94 \mathrm{~N}$ and area of contact $A=1.3976 \mathrm{~mm}^{2}$. Therefore, contact pressure $P_{\text {machining }}=N / A=731 \cdot 21 \mathrm{~N} \mathrm{~mm}^{-2}(0.73 \mathrm{GPa})$. The contact pressure in the machining test is $\sim 25$ times higher than that in wear test so it is not that surprising that there is no clear correlation between cutting tool performance and the wear coefficients as obtained via ball-on-disc test.

Unlike flank surface of the inserts, the rake surface has undergone significant wear during machining. Samples deposited at lower target frequency $(100 \mathrm{kHz})$ such as S2, S3 and S4 have significant amount of crater wear only after $3 \mathrm{~min}$ of machining. Sample S2 shows considerable removal of the coating from rake face whereas sample S3 shows complete removal of coating. Nature of crater wear of sample S4 is less than these two, possibly indicating advantage of depositing at higher temperature $\left(350^{\circ} \mathrm{C}\right)$. However, the scenario is different for samples deposited at higher target frequency (200 $300 \mathrm{kHz}$ ). Those samples (S5 to S9) show almost no removal of coating from rake surface. However, inserts S5, S6 and S8 show signs of grooving wear at the rake face whereas inserts $\mathrm{S} 7$ and $\mathrm{S} 9$ do not show any grooving wear. After 3 min of machining, the average flank wears for these two inserts (S7 and S9) are only 33 and $30 \mu \mathrm{m}$ respectively. This clearly indicates the advantage of depositing at a higher temperature $\left(>300^{\circ} \mathrm{C}\right)$ and higher target frequency $(>250 \mathrm{kHz})$. High deposition temperature and high target frequency improves ionisation during deposition providing better machining performance. Figure 6 provides a clear idea of the nature of crater and flank wear for inserts $\mathrm{S} 4$ to $\mathrm{S} 9$ after $3 \mathrm{~min}$ of machining. From Fig. 5, it is clear that insert S7 and S9 perform the best among all inserts as tool wear is negligible for them. Therefore, elemental area mapping of these two inserts (S7 and S9) have been carried out after 3 min of dry turning of SAE 1037 steel, as shown in Fig. 6. It is clearly visible that both $\mathrm{Ti}$ and $\mathrm{Al}$ are equally present all over the rake face revealing no crater wear or grooving wear upon machining.

\section{Conclusions}

TiAlN coating could be realised using pure $\mathrm{Ti}$ and $\mathrm{Al}$ targets in dual cathode machine with acceptable composite hardness (21-25 GPa), scratch adhesion (55-86 N) and wear coefficient $\left(5-10 \times 10^{-6} \mathrm{~mm}^{3} \mathrm{~N}^{-1} \mathrm{~m}^{-1}\right)$. The coating composition was not directly dependent on deposition temperature or target frequency individually; but increasing both the parameters increased the Al percentage in the coating, thus Al rich coatings were produced. The fatigue fracture resistance of the as deposited TiAlN coating was found to be better than a commercial TiAlN coating of similar $\mathrm{Ti} / \mathrm{Al}=1: 1$ ratio deposited on cemented carbide. The wear coefficient was improved with increase in deposition temperature when depositions were done at high target frequency $(250 \mathrm{kHz})$ but the similar trend was not followed at lower target frequency $(100 \mathrm{kHz})$. The wear coefficient was found to be lowest $\left(5.6 \times 10^{-6} \mathrm{~mm}^{3} \mathrm{~N}^{-1} \mathrm{~m}^{-1}\right)$, when deposition was done simultaneously at high temperature $\left(350^{\circ} \mathrm{C}\right)$ and high target frequency $(250 \mathrm{kHz})$.

There was almost no correlation between wear coefficients of the coated inserts and their machining performance in terms of flank wear due to the wide difference between wear test and machining test conditions. The flank wear remained low for all the inserts after 3 minutes of dry turning of SAE 1037 steel (cutting velocity of $160 \mathrm{~m} \mathrm{~min}^{-1}$, feed of $0.2 \mathrm{~mm} \mathrm{rev}^{-1}$ and depth of cut of $2 \mathrm{~mm}$ ). The crater wear was significant for the samples deposited at low target frequency 
$(100 \mathrm{kHz})$ whereas the samples deposited at high target frequency $(200-300 \mathrm{kHz})$ did not reveal any coating removal from rake face. Moreover, coatings deposited at higher temperature $\left(>300^{\circ} \mathrm{C}\right)$ and at higher target frequency $(>250 \mathrm{kHz})$ were free from both crater wear and grooving wear after 3 min of machining. Thus the mechanical properties and machining performance of TiAlN coatings deposited by dual cathode pulsed dc CFUBMS were favourably influenced by a simultaneous increase in target frequency and deposition temperature.

\section{Acknowledgement}

P. Mandal and S. Paul gratefully acknowledge the funding support that they received from Department of Science and Technology, Government of India, under FIST Programme (Sanction No. SR/FST/ET-II-003/ 2000 dated $20 \cdot 5 \cdot 2002$ ).

\section{References}

1. J. R. Peterson: J. Vac. Sci. Technol., 1974, 11, (4), 715

2. W. D. Munz: J. Vac. Sci. Technol. A, 1986, 4A, 2717.

3. P. J. Kelly and R. D. Arnell: Vacuum, 2000, 56, 159.

4. G. S. Kim, S. Y. Lee and J. H. Hahn: Surf. Coat. Technol., 2005, 193, 213.

5. P. W. Shum, K. Y. Li, Z. F. Zhou and Y. G. Shen: Wear, 2004, 257, 1030 .

6. M. Astrand, T. I. Selinder and M. E. Sjostrand: Surf. Coat. Technol., 2005, 200, 625.

7. O. Zywitzki, H. Klostermann, F. Fietzke and T. Modes: Surf. Coat. Technol., 2006, 200, 6522.

8. H. C. Barshilia, K. Yogesh and K. S. Rajam: Vacuum, 2008, 83, 427

9. J. Musiland and H. Hruby: Thin Solid Films, 2000, 365, 104.
10. B. D. Beake, G. S. Fox-Rabinovich, S. C. Veldhuis and S. R. Goodes: Surf. Coat. Technol., 2009, 203, 1919.

11. V. H. Derflinger, A. Schutze and M. Ante: Surf. Coat. Technol., 2006, 200, (16-17), 4693.

12. G. S. Fox-Rabinovich, A. I. Kovalev, M. H. Aguirre, B. D. Beake, K. Yamamoto, S. C. Veldhuis, J. L. Endrino, D. L. Wainstein and A. Y. Rashkovskiy: Surf. Coat. Technol., 2009, 204, 489.

13. T. Zhou, P. Nie, X. Cai and P. K. Chu: Vacuum, 2009, 83, 1057.

14. Y. He, I. Apachitei, J. Zhou, T. Walstock and J. Duszczyk: Surf. Coat. Technol., 2006, 201, 2534.

15. S. PalDey and S. C. Deevi: Mater. Sci. Eng. A, 2003, A342, 58.

16. A. E. Santana, A. Karimi, V. H. Derflinger and A. Schutze: Tribol. Lett., 2004, 17, (4), 689.

17. B. D. Beake, S. R. Goodes and J. F. Smith: Surf. Eng., 2001, 17, 187.

18. B. D. Beake, G. A. Bell, S. R. Goodes, N. J. Pickford and J. F. Smith: Surf. Eng., 2010, 26, 37.

19. G. S. Fox-Rabinovich, B. D. Beake, J. L. Endrino, S. C. Veldhuis, R. Parkinson, L. S. Shuster and M. S. Migranov: Surf. Coat. Technol., 2006, 200, 5738.

20. G. Boothroyd: Fundamentals of metal machining and machine tools'; 1975, McGraw Hill.

21. S. J. Bull, R. Kingswell and K. T. Scott: Surf. Coat. Technol., 1996, 82, 218

22. J. L. Mo, M. H. Zhu, B. Lei, Y. X. Leng and N. Huang: Wear, 2007, 263, 1423.

23. X. Li, C. Li, Y. Zhang, H. Tang, G. Li and C. Mo: Appl. Surf. Sci., 2010, 256, 4272

24. J. Takadoum and H. H. Bennani: Surf. Coat. Technol., 1997, 96, 272.

25. S. J. Bull, D. S. Rickerby, T. Robertson and A. Hendry: Surf. Coat. Technol., 1988, 36, 743.

26. K. D. Bouzakis, S. Hadjiyiannisa, G. Skordarisa, I. Mirisidisa, N. Michailidisa, K. Efstathioua, E. Pavlidoub, G. Erkensc, R. Cremerc, S. Rambadtc and I. Wirth: Surf. Coat. Technol., 2004, 177-178, 657.

27. E. Usui, T. Shirakashi and T. Kitagawa: Trans. ASME, 1978, 100, 


\section{Authors Queries}

Journal: Surface Engineering

Paper: 1265

Title: Effect of deposition parameters on TiAIN coating using pulsed DC CFUBMS

Dear Author

During the preparation of your manuscript for publication, the questions listed below have arisen. Please attend to these matters and return this form with your proof. Many thanks for your assistance

\begin{tabular}{|l|l|l|}
\hline $\begin{array}{l}\text { Query } \\
\text { Reference }\end{array}$ & Query & Remarks \\
\hline 1 & $\begin{array}{l}\text { Please confirm the running head } \\
\text { is correct. }\end{array}$ & \\
\hline 2 & $\begin{array}{l}\text { Please confirm the affiliation of } \\
\text { the authors. }\end{array}$ & \\
\hline
\end{tabular}

